\section{International Scientific Journal Theoretical \& Applied Science}

Gauhar Sarsenbaevna Borankulova Ph.D., i.o.dotsent TarSU them. M.H.Dulati b.gau@mail.ru

Aigul Turyszhanovna Tungatarova Ph.D., i.o.dotsent TarSU them. M.H.Dulati at.tu@mail.ru

SECTION 4. Computer science, computer engineering and automation.

\title{
SOFTWARE FOR RESEARCH WORK
}

Abstract: The article discusses the issues of software in the educational process, namely the automation of the examination of the training program by module. The description of the information system "Automation of examination of the training program by module" is given, which is a complex of program modules for the organization of access (authorization) of the examination of the training program.

Key words: module training program, automation, expertise, software.

Language: English

Citation: Borankulova GS, Tungatarova AT (2017) SOFTWARE FOR RESEARCH WORK. ISJ Theoretical \& Applied Science, 05 (49): 146-150.

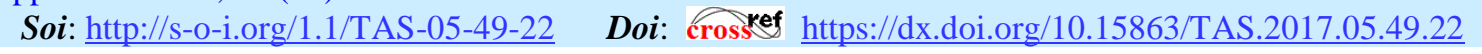

\section{Introduction}

Software for information systems A set of regular application programs, descriptions and instructions for their use, designed for technical operation of autonomous computers, computer workstations of computer systems and networks, as well as the participation of programmers in the creation and maintenance of software products. The main software in the educational process is the automation of the educational process, which allows you to solve problems in: creating and supporting information resources in the university; Accounting information on the structure of the university and structural units; Accounting and personnel management; Implementation of automated workflow at faculties and departments; Accounting of curricula; Load planning departments; Teacher load planning; Examination of the training program by module; Accounting of information about applicants, the course of entrance examinations at the university; Implementation of automated workflow in the work of the selection committee; Tasks of statistical observation; Various tasks for analytical processing; Accounting of information about students, their academic performance and management of student contingent; and etc.All software modules used in the educational process are informationally connected with the automated data bank and with each other and have functional independence. Work with the software used in the subsystem is organized in an interactive mode and creates conditions for processing information in real time. This allows you to organize access to the information subsystem with a query about the status of the control object at any time and receive operational information.The software requires high reliability, efficient use of computer resources, structural, modularity, cost-effectiveness, friendliness with respect to users, and so on.The software for automation of the educational process ensures the coordinated operation of all PC devices and their interaction with the user. As part of the software allocate common software and application software.Asa common software, various operating systems for local PCs and operating systems of local computer networks are used. The main purpose of the common software is the launch of application programs and the management of their execution. The special software of the automated workplace usually consists of unique programs and functional packages application programs. It is from the functional software that the specific specialization of workplace automation depends. The software must have adaptive and customizable properties for a particular application in accordance with the user's requirements.

\section{Materials and Methods}

Basic software tools for creating automated workplaces for the automation of the educational process are software for the preparation of texts, spreadsheets, software for automating the creation and maintenance of databases, finding the required 
information for the preparation of various documents, accounting programs, specialized processing programs Commercial information. The integrated packages of application programs, which include a text editor, a table processor, a database management system, as well as a specific command file for setting up software for a specific type (mode) of information processing, have become very popular.A special role is assigned to the organization of the user interface. The graphical user interface is the type of screen representation in which the user can select commands, run tasks and view file lists, pointing to icons or items in the menu lists shown on the screen. Actions can, as a rule, be performed with the mouse, or by pressing a key on the keyboard.The key to creating an effective interface is the rapid, as far as possible, development of operators simple conceptual interface model. This is done through consistency. The concept of consistency is that when working with a computer, the user forms a system for waiting for identical reactions to the same actions, which constantly supports the user interface model.Another component of the interface is the property of its concreteness and clarity. This is done by applying the panel plan, using colors and other expressive techniques. Ideas and concepts then acquire a physical expression on the screen with which the user directly communicates.A wellexecuted interface allows to solve the main task - to ensure the convenience of working with the user application.Before the appearance of the user interface, a splash screen appears, then a dialog box appears asking for the password to gain access, after the correct access is entered, the user interface window appears, if the password is incorrectly entered, a dialog box appears with the message "You have not been authorized"Information system "Automation of examination of the training program by module" is a set of software modules for the organization of access (authorization), viewing and editing the database,editing the base of synonyms, forming the catalogs of the training program, writing to the database, comparing. At the beginning, the access module is launched, which requests a password, after reconciliation, the Data Module connects the database and runs the form to generate the key file to the discipline. Then the main form is launched, which consists of the Exit tab, View and editing of the database, Synonyms, About the program, About the author.The "Keyword Base Formation" form is designed for typing directly from the keyboard in the keyword program window to the discipline. Keywords can be pre-designed and saved as a file with the extension * .keu, which is entered in the form "Identifier".The "Synonyms" form allows you to create a dictionary of synonyms, supplement it or remove unnecessary words from it.The "Keyword Base" form allows you to view the list of information on the discipline, faculty, department entered in the database and to see the list of keywords for discipline. If necessary, you can delete the selected entry from the list.

Technological support - the basis of automated information technology, which implements information processes in automated systems of organizational management, meets information needs of specialists in solving professional problems.Means of information processing - computers form the basis of technical support of an automated workplace network and can include powerful, medium and small computers. A characteristic feature of the practical use of technical means in organizational and economic management is now the transition to decentralized processing on the basis of PC.Delphi 7 is an application development environment based on object-oriented programming. This programming technology is the foundation that allows you to implement all the functionality of Delphi 7 . When creating applications based on the finished components using properties, methods and predefined event handlers, you can get by with a small code. For the developer, this means that when developing the user interface of their applications, it can receive significant time savings.A package of visual programming Delphi, allows you to create fairly effective applications for working with databases. The scheme of interaction of program modules is shown in the figure 1 . 


\begin{tabular}{l|lrl|l|ll} 
& ISRA (India) & $=\mathbf{1 . 3 4 4}$ & SIS (USA) & $=\mathbf{0 . 9 1 2}$ & ICV (Poland) & $=\mathbf{6 . 6 3 0}$ \\
Impact Factor: & ISI (Dubai, UAE) $=\mathbf{0 . 8 2 9}$ & PUHU (Russia) $=\mathbf{0 . 2 3 4}$ & PIF (India) & $=\mathbf{1 . 9 4 0}$ \\
& GIF (Australia) & $\mathbf{0 . 5 6 4}$ & ESJI (KZ) & $=\mathbf{3 . 8 6 0}$ & IBI (India) & $\mathbf{4 . 2 6 0}$
\end{tabular}

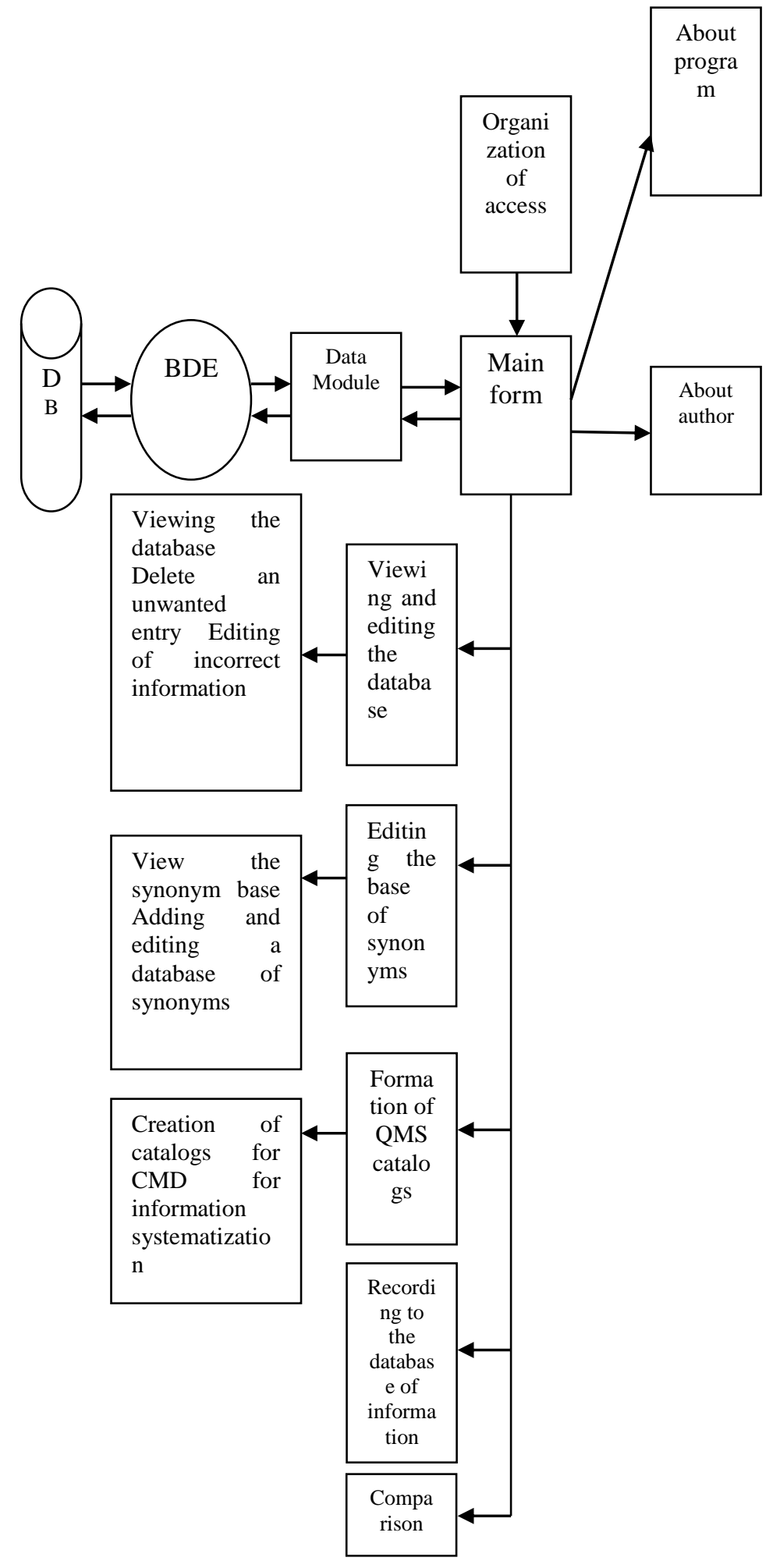

Figure 1 - The inter connection of software module. 


\section{Conclusion}

Creating applications using Delphi and using them requires certain resources of computer technology.The preference for using Delphi was also based on a number of the following advantages. The language of Pascal is still the best programming language. And the language of Object Pascal, unlike Borland (Turbo) Pascal and other modern application development tools of the same class, has built-in support for a modular methodology for creating applications, because each visual form is automatically placed in accordance with a separate module. Therefore, the creation of Windows applications using visual software development technology does not begin with the simplest operators, but with the ready visual components for which code is automatically generated in the form of much larger syntactic units (classes, properties, methods, modules).Delphi in terms of tools for developing Windows applications includes a highperformance compiler. Therefore, the Delphi compiler from the ObjectPascal language is one of the most productive in the world.The standard software for the design and use of applications for working with the database include operating systems, standard database management systems and modern application design tools.Processing programs include translators, service programs, sorting programs mergers and utilities; Using them traditionallyin process automation. In addition to translators, the operating system includes service programs: link editor, loader and debugging system.

Databases (Paradox, dBase, FoxPro, Access, etc.) also require fairly decent computer technology for their effective use. For each of them there are minimal volumes of operational and disk memory and minimal computer speed under which the database management system will work effectively.

For stable operation and ensuring the integrity and correctness of reading / writing data from the database, uninterrupted power is required for the computer. The cheapest and most reliable device is suitable: UPS PC-STAR 1400VA.

For the reservation of information, you can use: CD-RW Drive 40/12/40 SAMSUNG SW-240BRNS with Nero software, writing to CDs (CD-R, CD$\mathrm{RW})$. This backup strategy will protect information from various emergencies that may occur with the computer that stores the database. And also, if necessary, it is possible to restore the information.

For stable and reliable operation of the information system, the computer must have the Windows 2000 Professional operating system installed. The operating system Windows 2000 is the latest version of Microsoft's Windows NT operating system. Identification of the user includes procedures to make sure that the user is exactly who he claims to be. The operating system Windows 2000 provides several different ways to perform this operation. The traditional combination of "user name / password" is time-tested, but human memory, unfortunately, is unreliable.

You also need to install the application package Microsoft Office 2000 Professional or another version.

The program «Automation of examination of the training program by module $»$ is an independent module that operates in the environment of Windows 98 and higher.

\section{References:}

1. Emelyanova NZ (2005) "Fundamentals of the construction of automated information systems: a tutorial" / N.Z. Emelyanova, TL. Partyka, I.I. Popov - M .: Forum: Infra-M. $412 \mathrm{p}$.

2. Bidaybekov EY, Grigoriev SG, Grinshkun VV (2002) Information integration and analysis of the educational field in the development of e-learning tools. // Monograph. / Alma-Ata: MoE of the RK, ASU. Abay. - 2002, 100 p.

3. Bidaybekov EY, Grinshkun VV (2001) Theoretical and technological approach to the development of electronic means of teaching. // Bulletin of the ASU.
Abay.Physico-mathematical series. AlmaAta.. № 2 (4).p.32-37.

4. Palchevsky BP, Fridman LS, Seleznev IF (1998) Educational-methodical complex of teaching aids. Part 1. Theoreticalbasis. Mn..-120 p.

5. Rudakov A (2005) Technology of Software Development: Proc. Allowance. - Moscow: Publishing Center "Academy".

6. Akulaeva OV (2007) Designing of educational and methodical support of modules of the innovative educational program Text : methodical grant / O.V. Akulaev [and others]; under. Ed. S.A. Goncharova.SPb .: RGPU them. AI Herzen. -159 p. 
\begin{tabular}{l|lrl|l|ll} 
& ISRA (India) & $=\mathbf{1 . 3 4 4}$ & SIS (USA) & $=\mathbf{0 . 9 1 2}$ & ICV (Poland) & $=\mathbf{6 . 6 3 0}$ \\
Impact Factor: & ISI (Dubai, UAE) $=\mathbf{0 . 8 2 9}$ & PUHL (Russia) $=\mathbf{0 . 2 3 4}$ & PIF (India) & $=\mathbf{1 . 9 4 0}$ \\
& GIF (Australia) & $\mathbf{0 . 5 6 4}$ & ESJI (KZ) & $=3.860$ & IBI (India) & $=\mathbf{4 . 2 6 0}$ \\
& JIF & $=\mathbf{1 . 5 0 0}$ & SJIF (Morocco) & $=\mathbf{2 . 0 3 1}$ & & \\
\hline
\end{tabular}

7. Linkov VM, Lin'kova AV (2003) Questions of automation of management of educational process in high school. - ITO.

8. Khomonenko AD, Tsygankov VM, Maltsev MG (2000) Database. St. Petersburg: KORONA print.

9. Khetagurov YA (2002) Fundamentals of construction of automated information processing and control systems (ASOIU): Textbook. Moscow: MEPhI. 252 p.

10. Norenkov IP (2002) Fundamentals of Computer-Aided Design: Proc. For universities. 2 nd ed., Revised. And additional. Moscow: Izd. MSTU. N.E. Bauman. - 336 p. 